\title{
Treatment and re-operation rates in one thousand and three hundred tibial fractures from the Swedish Fracture Register
}

\author{
David Wennergren ${ }^{1,2} \cdot$ Carl Bergdahl ${ }^{1,2} \cdot$ Amanda Selse $^{1} \cdot$ Jan Ekelund $^{3} \cdot$ Mikael Sundfeldt $^{2} \cdot$ Michael Möller $^{1,2}$
}

Received: 24 May 2020 / Accepted: 25 July 2020 / Published online: 2 August 2020

(c) The Author(s) 2020

\begin{abstract}
Purpose Approximately, 50 persons per 100,000 per year sustain a tibial fracture. There is, however, a lack of large cohort studies that describe the treatment and re-operation frequencies of tibial fractures. The aim of this study was to describe the treatment and re-operation rates of tibial fractures in all segments of the tibia.

Methods Data related to all patients aged 16 and above treated for tibial fractures (ICD-10 S82.10-31) at Sahlgrenska University Hospital in 2011-2015 were extracted from the Swedish Fracture Register. To make sure all re-operations were included in the study, the operation planning system was checked for all patients included in the study.

Results The study comprised 1371 tibial fractures - 712 proximal, 417 diaphyseal and 242 distal tibial fractures. Among the proximal and distal tibial fractures, plate fixation was the most commonly used surgical method, whereas among tibial shaft fractures, an intramedullary nail was the most commonly used surgical method. Almost $30 \%$ (29.8\%) of all surgically treated tibial fractures underwent re-operation. Among proximal tibial fractures, $24.0 \%$ underwent re-operation; tibial shaft fractures $37.0 \%$ and distal tibial fractures $26.8 \%$. Re-operations due to infection were more or less equally common in all segments (3.9-5.4\%).

Conclusion This study describes the treatment and re-operation rates after tibial fractures in a cohort of 1371 tibial fractures at Sahlgrenska University Hospital during a period of 5 years. The study shows an overall re-operation rate of $29.8 \%$ for fractures in all segments of the tibia.
\end{abstract}

Keywords Tibial fracture $\cdot$ Treatment $\cdot$ Re-operation $\cdot$ Fracture register

\section{Abbreviations}

AO Arbeitsgemeinschaft für osteosynthesefragen

OTA Orthopaedic Trauma Association

SFR Swedish Fracture Register

ICD-10 International Classification of Diseases Tenth Revision

David Wennergren

david.wennergren@vgregion.se

1 Institute of Clinical Sciences, Sahlgrenska Academy, University of Gothenburg, Gothenburg, Sweden

2 Department of Orthopaedics, Sahlgrenska University Hospital, SE-413 45 Mölndal, Gothenburg, Sweden

3 Centre of Registers, Western Healthcare Region, Gothenburg, Sweden

\section{Introduction}

Approximately, 50 persons per 100,000 and year sustain a tibial fracture [1]. During the past 20 years, the treatment of tibial fractures has evolved. New opportunities with anatomic plates and modern intramedullary nails have been developed. There is, however, a lack of large cohort studies that describe the treatment and re-operation frequencies of tibial fractures in everyday practice.

A few recent studies of different aspects of specific types of tibial fracture have reported re-operation rates after the treatment of tibial fractures [2-6]. To the best of our knowledge, there is, however, no previous register-based study that describes the treatment and re-operation rates for fractures in all segments of the tibia.

Some randomised controlled trials of the treatment of tibial fractures have been performed [3, 7-9]. They often focus on specific topics, such as plate fixation versus intramedullary nailing or reamed versus non-reamed intramedullary nailing in certain fracture types with specific inclusion and 
exclusion criteria. The Swedish Fracture Register (SFR), on the other hand, prospectively collects data on all patients with all types of fracture, regardless of treatment $[10,11]$. Several validity and epidemiological studies based on data from the SFR have been published [1, 12-21]. Registerbased studies, such as studies based on data from the SFR, include all patients and fractures, regardless of treatment, and can describe the current treatment and results of the treatment algorithms being used in current clinical practice.

The aim of this study was to describe the treatment and re-operation rates of tibial fractures in all segments of the tibia for a cohort of consecutive tibial fractures at one large hospital over a period of 5 years.

\section{Materials and methods}

Data related to all patients treated for tibial fractures (ICD-10 S82.10-31) at Sahlgrenska University Hospital in 2011-2015 were extracted from the SFR. This includes isolated tibial fractures as well as tibial fractures as part of multiply injured patients. Sahlgrenska University Hospital covers a population of approximately 530,000 inhabitants aged 16 and above in the primary catchment area and 1,700,000 inhabitants (all ages) in the secondary catchment area and is the only hospital in the area treating tibial fractures [1]. The study is based on the same cohort as a previous study on epidemiology and incidence of tibial fractures. Data such as mean age, range and distribution among fracture classes are described in detail in that publication [1]. The data extraction was performed in 2018 and the minimum follow-up period is 2 years (range 2-8 years). The data consist of information on the patient's date of birth, the date and cause of the injury, high- or low-energy trauma, fracture classification according to AO/OTA, all treatments of each fracture, including primary treatments, planned secondary surgery and re-operations, as well as the reason for re-operation [22, 23]. Data on ligament injuries are not collected in the SFR.

All treatments performed for a fracture were registered in the SFR, i.e. primary treatments, planned secondary treatments and re-operations. Decision regarding treatment for each fracture was decided by the attending orthopaedic surgeon. Surgical as well as non-surgical treatments were registered. Non-surgical treatment included treatment with plaster, orthosis and fractures where no active treatment was given. When re-operations are performed, the reoperation together with the reason for the re-operation is registered, e.g. non-union, malunion, infection and patient discomfort. Patient discomfort was typically when internal fixation material, e.g. a locking screw in an intramedullary nail, caused the patient local pain. The design of the SFR and the registration process have been described in detail in two earlier publications $[10,11]$. Like a previous study of epidemiology in the same cohort, the current study includes patients aged 16 and above [1]. At the Department of Orthopaedics, Sahlgrenska University Hospital there are more or less well defined traditions and practice of how different types of tibial fractures are treated. There are, however, no formal protocols concerning treatment choice. In clinical practice it is the surgeon's choice how to treat the fracture at hand. The same applies to implant removal.

To make sure all re-operations were included in the study, the operation planning system was checked for all patients included in the study. If a treatment not registered in the SFR was detected, the medical chart was reviewed and missed treatments were registered in the SFR. Subsequently, a new data extraction was made from the SFR on which the calculations and analysis for the study were based.

\section{Statistical analysis}

The study only contains descriptive statistics. No statistical tests between groups and no sample size calculation were therefore performed. All statistics for tables and figures in the study were calculated with IBM SPSS 25 and SAS v 9.4.

\section{Ethics}

The study was approved by the Central Ethical Review Board, Gothenburg (Ref nr: 594-16).

\section{Human and animal rights}

This is a register study and no Human and Animal Rights were violated.

\section{Results}

\section{Treatment}

The study comprised 1371 tibial fractures -712 proximal, 417 diaphyseal and 242 distal tibial fractures. The majority (66\%) of tibial fractures were treated surgically, but $34 \%$ were treated non-surgically (Fig. 1). For all tibial fractures, 1672 surgical procedures were performed -888 primary surgical procedures, 302 planned secondary procedures (e.g. staged procedures such as intramedullary nailing or plate fixation after temporary external fixation) and 463 reoperations. Nineteen tibial fractures were primarily assigned to non-surgical treatment, but, at an early stage, they were converted to surgical treatment after non-surgical treatment was considered inappropriate, e.g. due to a more severe dislocation found at an early x-ray check-up ("Surgical treatment after failed non-surgical treatment") (Table 1). 
Fig. 1 Distribution of treatment of tibial fractures according to segment of tibia
Table 1 Number of treatments performed for all tibial fractures at Sahlgrenska University Hospital in 2011-2015

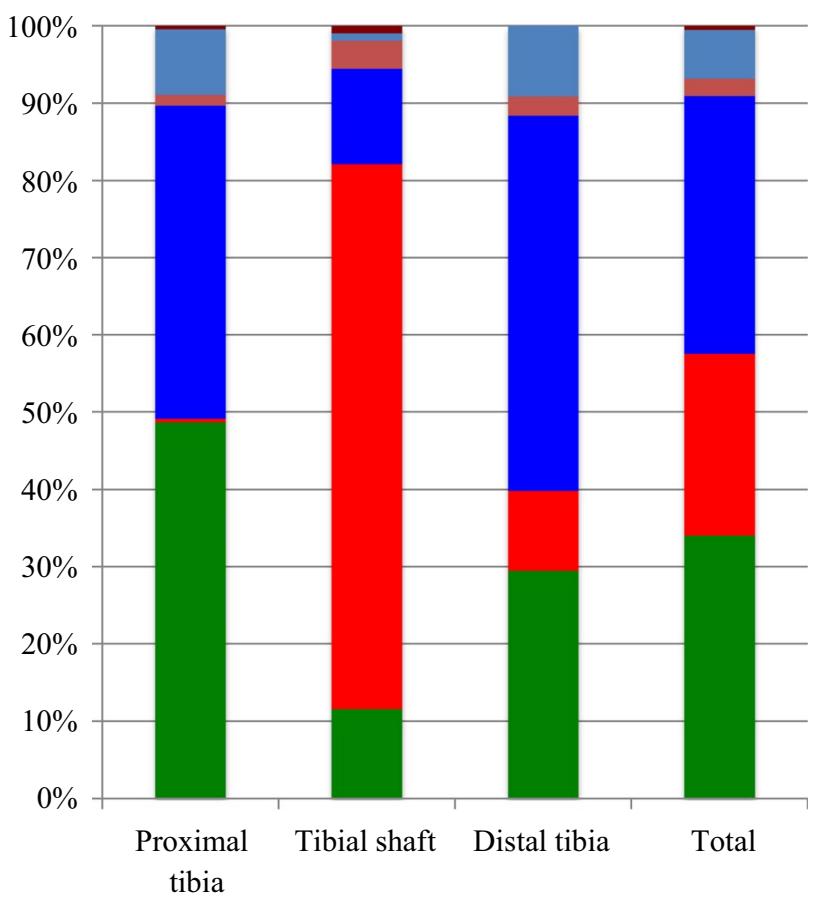

Amputation

Other surgical treatment

- External fixation

- Plate fixation

- Intra-medullary nail

Non-surgical treatment

\begin{tabular}{lcccc}
\hline & \multicolumn{2}{l}{ Segment } & & \\
\cline { 2 - 5 } & $\begin{array}{l}\text { Proximal } \\
(N=712)\end{array}$ & Shaft $(N=417)$ & Distal $(N=242)$ & $\begin{array}{l}\text { Total } \\
(N=1371)\end{array}$ \\
\hline Non-surgical treatment & 352 & 62 & 75 & 489 \\
Primary surgical treatment & 358 & 361 & 169 & 888 \\
Planned secondary procedure & 97 & 83 & 122 & 302 \\
Surgical treatment after failed non-surgi- & 7 & 10 & 2 & 19 \\
$\quad$ cal treatment* & 6 & 37 & 14 & 57 \\
Re-operation due to non-union & 29 & 17 & 12 & 58 \\
Re-operation due to malunion & 32 & 20 & 14 & 66 \\
Re-operation due to infection & 4 & 22 & 14 & 118 \\
Re-operation due to implant failure & 42 & 62 & 23 & 126 \\
Re-operation due to patient discomfort & 40 & 63 & & \\
Re-operation due to other reason & 40 & & & 14 \\
\hline
\end{tabular}

*Fractures that were primarily assigned to non-surgical treatment, but which at an early stage were converted to surgical treatment after non-surgical treatment was considered inappropriate

The completeness of the registration of treatments (the extent to which the treatments that were performed had been initially registered in the SFR) was $99.1 \%$ for primary procedures, $88.7 \%$ for planned secondary surgery and $63 \%$ for re-operations (Table 2).

Non-surgical treatment was chosen in 341/699 (49\%) of proximal tibial fractures, 48/411 (12\%) of tibial shaft fractures and 68/237 (29\%) of distal tibial fractures (Table 3). Table 3 also shows that, among the proximal and distal tibial fractures, plate fixation is the most commonly used surgical method, whereas among tibial shaft fractures, intramedullary
Table 2 Number of initially missed registrations of procedures and completeness according to type of procedure for tibia fractures at Sahlgrenska University Hospital 2011-2015

\begin{tabular}{lccl}
\hline & $\begin{array}{l}\text { Missed } \\
\text { registra- } \\
\text { tions }\end{array}$ & $\begin{array}{l}\text { Total number } \\
\text { of procedures }\end{array}$ & $\begin{array}{l}\text { Com- } \\
\text { pleteness } \\
(\%)\end{array}$ \\
\hline Primary procedure & 12 & 1396 & 99.1 \\
Planned secondary surgery & 34 & 302 & 88.7 \\
Re-operation & 171 & 462 & 63.0 \\
Total & 217 & 2160 & 90.0 \\
\hline
\end{tabular}


Table 3 Treatment of tibial fractures according to AO/OTA class at Sahlgrenska University Hospital in 2011-2015

\begin{tabular}{|c|c|c|c|c|c|c|c|}
\hline AO/OTA class & Non-surgical & IM nail & Plate fixation & External fixation & $\begin{array}{l}\text { Other surgical } \\
\text { treatment* }\end{array}$ & Amputation & Total \\
\hline \multicolumn{8}{|c|}{ Treatment, number of fractures (\%) } \\
\hline $41-\mathrm{A} 1$ & $38(64)$ & $0(0)$ & $1(2)$ & $0(0)$ & $20(34)$ & $0(0)$ & 59 \\
\hline $41-\mathrm{A} 2$ & $27(49)$ & $1(2)$ & $26(47)$ & $1(2)$ & $0(0)$ & $0(0)$ & 55 \\
\hline $41-\mathrm{A} 3$ & $1(8)$ & $1(8)$ & $10(83)$ & $0(0)$ & $0(0)$ & $0(0)$ & 12 \\
\hline $41-\mathrm{B} 1$ & $119(66)$ & $1(1)$ & $45(25)$ & $0(0)$ & $15(8)$ & $0(0)$ & 180 \\
\hline $41-\mathrm{B} 2$ & $107(77)$ & $0(0)$ & $24(17)$ & $0(0)$ & $8(6)$ & $0(0)$ & 139 \\
\hline $41-\mathrm{B} 3$ & $37(29)$ & $0(0)$ & $81(64)$ & $0(0)$ & $8(6)$ & $0(0)$ & 126 \\
\hline $41-\mathrm{C} 1$ & $9(20)$ & $0(0)$ & $33(73)$ & $0(0)$ & $3(7)$ & $0(0)$ & 45 \\
\hline $41-\mathrm{C} 2$ & $1(5)$ & $0(0)$ & $14(74)$ & $2(11)$ & $2(11)$ & $0(0)$ & 19 \\
\hline $41-\mathrm{C} 3$ & $2(3)$ & $0(0)$ & $52(81)$ & $7(11)$ & $1(2)$ & $2(3)$ & 64 \\
\hline Total 41 & 341 (49) & $3(0.4)$ & $286(41)$ & $10(1)$ & $57(8)$ & $2(0.3)$ & 699 \\
\hline $42-\mathrm{A} 1$ & $15(13)$ & $82(73)$ & $12(11)$ & $4(4)$ & $0(0)$ & $0(0)$ & 113 \\
\hline $42-\mathrm{A} 2$ & $6(12)$ & $38(75)$ & $3(6)$ & $1(2)$ & $2(4)$ & $1(2)$ & 51 \\
\hline $42-\mathrm{A} 3$ & 19 (29) & $41(62)$ & $2(3)$ & $2(3)$ & $2(3)$ & $0(0)$ & 66 \\
\hline $42-\mathrm{B} 1$ & $4(10)$ & $31(76)$ & $5(12)$ & $1(2)$ & $0(0)$ & $0(0)$ & 41 \\
\hline $42-B 2$ & $2(4)$ & $38(76)$ & $9(18)$ & $1(2)$ & $0(0)$ & $0(0)$ & 50 \\
\hline $42-\mathrm{B} 3$ & $1(4)$ & $14(58)$ & $6(25)$ & $2(8)$ & $0(0)$ & $1(4)$ & 24 \\
\hline $42-\mathrm{C} 1$ & $0(0)$ & $26(84)$ & $5(16)$ & $0(0)$ & $0(0)$ & $0(0)$ & 31 \\
\hline $42-\mathrm{C} 2$ & $0(0)$ & $14(82)$ & $2(12)$ & $1(6)$ & $0(0)$ & $0(0)$ & 17 \\
\hline $42-\mathrm{C} 3$ & $1(6)$ & $8(44)$ & $6(33)$ & $3(17)$ & $0(0)$ & $0(0)$ & 18 \\
\hline Total 42 & 48 (12) & $292(71)$ & $50(12)$ & $15(4)$ & $4(1)$ & $2(0.5)$ & 411 \\
\hline $43-\mathrm{A} 1$ & $30(54)$ & $11(20)$ & $15(27)$ & $0(0)$ & $0(0)$ & $0(0)$ & 56 \\
\hline $43-\mathrm{A} 2$ & $2(29)$ & $1(14)$ & $4(57)$ & $0(0)$ & $0(0)$ & $0(0)$ & 7 \\
\hline $43-\mathrm{A} 3$ & $3(10)$ & $11(37)$ & $13(43)$ & $3(10)$ & $0(0)$ & $0(0)$ & 30 \\
\hline 43-B1 & $29(57)$ & $0(0)$ & $8(16)$ & $1(2)$ & $13(25)$ & $0(0)$ & 51 \\
\hline $43-\mathrm{B} 2$ & $1(8)$ & $0(0)$ & $9(69)$ & $0(0)$ & $3(23)$ & $0(0)$ & 13 \\
\hline 43-B3 & $1(8)$ & $0(0)$ & $9(69)$ & $0(0)$ & $3(23)$ & $0(0)$ & 13 \\
\hline $43-\mathrm{C} 1$ & $2(22)$ & $0(0)$ & $7(78)$ & $0(0)$ & $0(0)$ & $0(0)$ & 9 \\
\hline $43-\mathrm{C} 2$ & $0(0)$ & $2(18)$ & $8(73)$ & $1(9)$ & $0(0)$ & $0(0)$ & 11 \\
\hline $43-\mathrm{C} 3$ & $0(0)$ & $0(0)$ & $44(94)$ & $1(2)$ & $2(4)$ & $0(0)$ & 47 \\
\hline Total 43 & $68(29)$ & $25(11)$ & $117(49)$ & $6(3)$ & $21(9)$ & $0(0)$ & 237 \\
\hline Not able to classify & $6(50)$ & $0(0)$ & $1(8)$ & $0(0)$ & $2(17)$ & $3(25)$ & 12 \\
\hline Total & $463(34)$ & $320(24)$ & $454(33)$ & $31(2)$ & $84(6)$ & $7(0.5)$ & 1359 \\
\hline
\end{tabular}

* "Other surgical treatment" includes screw fixation, pin fixation, fixation with cerclage, etc

The percentage figures refer to the percentage within each row, i.e. the percentage per AO/OTA class. 10 fractures had missing information regarding main treatment and two fractures were classified as paediatric fractures and are not included in this table. As a result, the total number of fractures in the table is 1359

nailing is the most commonly used surgical method. A total of seven patients $(0.5 \%)$ underwent amputation. Three of these were fractures that were not possible to classify, two were proximal and two were tibial shaft fractures. However, no distal tibial fractures underwent amputation. Table 4 shows that five of these amputations were performed as reoperations, whereas the remaining two amputations were performed as primary treatments.

With regard to the proximal tibial fractures, the A1, A2, $\mathrm{B} 1$ and $\mathrm{B} 2$ fractures are the fractures most commonly treated non-surgically, whereas the A3, B3 and C fractures are most commonly treated surgically.

In terms of all fracture types among the tibial shaft fractures, the vast majority were treated surgically. Among all tibial shaft fractures, $71 \%$ were treated with intramedullary nailing. The A and B1 fractures were treated non-surgically in $10-29 \%$, whereas the other fracture classes were almost exclusively treated surgically. Plate fixation was less common for A fractures, but it occurs in all fracture classes. 


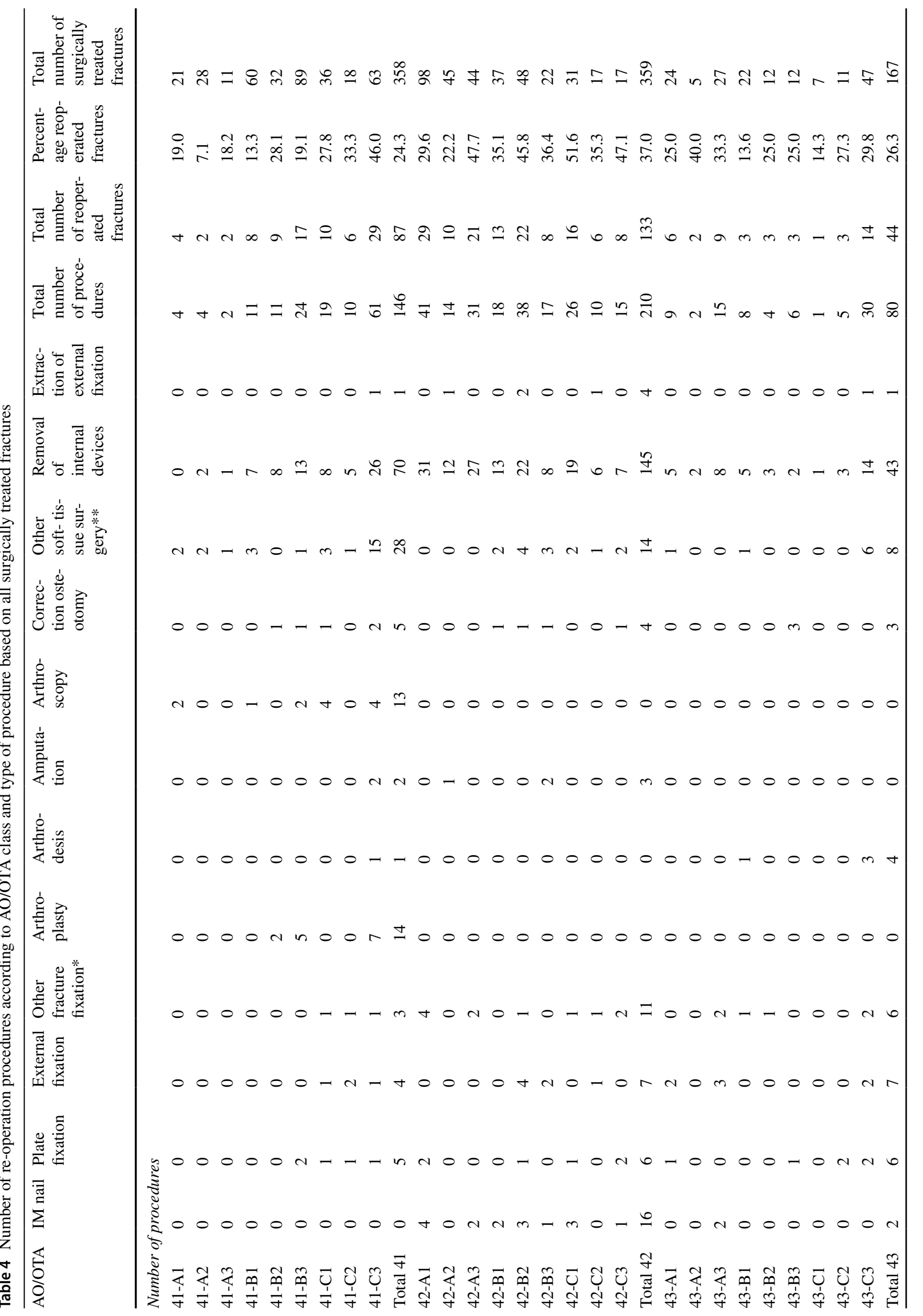




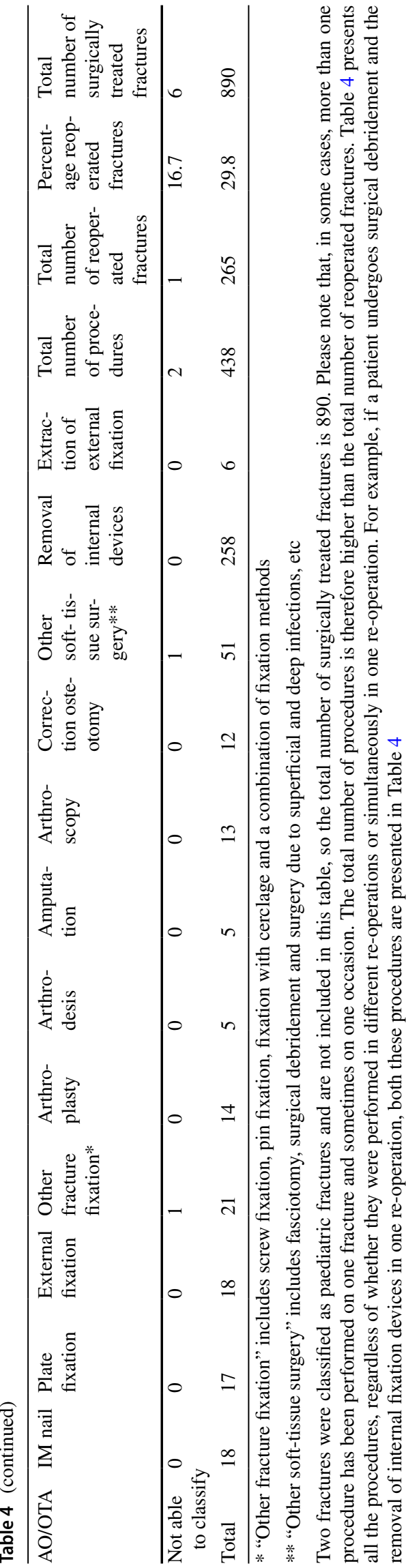

In terms of the distal tibia, among the $\mathrm{A} 1$ and $\mathrm{B} 1$ fractures, approximately half the fractures were treated nonsurgically (54\% and 57\%, respectively). For all other distal tibial fractures, the majority were treated surgically, most commonly with plate fixation, apart from some A fractures that were treated with intramedullary nailing.

\section{Re-operations}

$29.8 \%$ of all tibial fractures underwent re-operation (Table 4). Among proximal tibial fractures, $24.0 \%$ underwent re-operation, tibial shaft fractures $37.0 \%$ and distal tibial fractures $26.8 \%$ (Table 5). The AO/OTA classes with the highest re-operation rates were $41 \mathrm{C} 3(46.0 \%), 42 \mathrm{~A} 3$ (47.7\%), 42B2 (45.8\%), 42C1 (51.6\%), 42C3 (47.1\%) and 43A2 $(40.0 \%)$ (Table 4$)$. The removal of internal fixation devices is by far the most commonly performed re-operation (258/438 re-operations) (Table 4).

Table 5 presents percentage reoperated fractures according to reasons for re-operations per segment of the tibia. Among the proximal tibial fractures, $0.6 \%$ of the surgically treated fractures underwent re-operation due to non-union and $4.7 \%$ due to malunion. Among the tibial shaft fractures, it was the other way around $-5.2 \%$ of the surgically treated fractures underwent re-operation due to non-union, whereas $2.2 \%$ due to malunion. Among the distal tibial fractures, re-operation due to non-union and malunion were equally common $-4.2 \%$ each. Re-operations due to infection were more or less equally common in all segments of the tibia (3.9\%, $4.1 \%$ and $5.4 \%$, respectively).

Tables 6, 7, and 8 present the number of re-operations according to reason for re-operation and main treatment for each segment of the tibia. Twenty-three per cent of the proximal tibial fractures treated with plate fixation underwent re-operation. For tibial shaft fractures, the re-operation rates were the same for fractures treated with intramedullary nailing and plate fixation (39\% each) (Table 7). Among tibial shaft fractures treated with an intramedullary nail, 107 reoperations due to patient discomfort and "other reasons" were performed in 292 fractures, while, among tibial shaft fractures treated with plate fixation, ten re-operations due to patient discomfort and "other reasons" were performed in 51 fractures. Among the 51 tibial shaft fractures treated with plate fixation, seven re-operations were performed due to non-union, seven due to infection and five due to implant failure. Among the 292 tibial shaft fractures treated with an intramedullary nail, 19 re-operations were performed due to non-union, 11 due to infection and ten due to implant failure. Re-operations for malunion in tibial shaft fractures were only performed in fractures treated with an intramedullary nail.

Of the surgically treated tibial fractures, $3.1 \%$ underwent re-operation due non-union, $3.6 \%$ due to malunion, $4.3 \%$ 
Table 5 Percentage reoperated fractures according to segment of the tibia and reason for re-operations based on all surgically treated fractures

\begin{tabular}{lllllrrr}
\hline & Non-union (\%) & Malunion (\%) & Infection (\%) & $\begin{array}{l}\text { Implant fail- } \\
\text { ure }(\%)\end{array}$ & $\begin{array}{l}\text { Patient discom- } \\
\text { fort (\%) }\end{array}$ & $\begin{array}{l}\text { Other reason } \\
(\%)\end{array}$ & $\begin{array}{l}\text { Total re- } \\
\text { operations } \\
(\%)\end{array}$ \\
\hline Proximal tibia & 0.6 & & & 3.9 & 0.8 & 9.1 & 9.1 \\
Tibial shaft & 5.2 & 2.2 & 4.1 & 3.6 & 15.7 & 24.0 \\
Distal tibial & 4.2 & 4.2 & 5.4 & 3.6 & 7.7 & 37.1 & 8.3 \\
Total & 3.1 & 3.6 & 4.3 & 2.5 & 11.5 & 11 & 26.8 \\
\hline
\end{tabular}

due to infection and $2.5 \%$ due to implant failure (Table 5). The re-operation rates due to infection appear to be higher in patients 51-80 years of age (Fig. 2). For re-operations due to non-union, malunion and implant failure, however, there is no obvious difference in re-operation rates in the different age groups. Re-operations due to patient discomfort and other reasons appear to be more commonly performed in younger patients $($ age $\leq 60)$.

Of the 118 re-operations performed due to patient discomfort, 102 involved the removal of internal fixation devices. Of the 126 re-operations performed due to "other reasons", 73 involved the removal of internal fixation devices.

\section{Discussion}

\section{Treatment}

The most important finding in terms of treatment is that $49 \%$ of proximal tibial fractures, $12 \%$ of tibial shaft fractures and $29 \%$ of distal tibial fractures were treated non-surgically. The most commonly used surgical method was plate fixation for proximal and distal tibial fractures and intramedullary nailing for tibial shaft fractures. For most of the AO/OTA fracture classes, more than $60 \%$ of the fractures were treated with one specific method (e.g. non-surgical treatment, an intramedullary nail or plate fixation).

In many ways, there were clear patterns of treatment for tibial fractures in the current study, according to the $\mathrm{AO} /$ OTA classification. When reviewing the specific fracture classes, in 10 of 27 fracture classes, more than $75 \%$ of the fractures were treated with one specific treatment method (e.g. non-surgical treatment, an intramedullary nail or plate fixation) and, in 20 of 27 fracture classes, more than $60 \%$ are treated with one specific treatment method. This can be interpreted as meaning that the treatment choice for tibial fractures is often not controversial. Another interesting finding was that, in all segments, the "1" and " 2 " fractures (e.g. 41A1 and A2, 41B1 and 2, 43A1 and 43B1) appear to be more commonly treated non-surgically, whereas the more complex " 3 " fractures appear to be treated surgically to a larger extent. This supports the idea that the AO/OTA classification system is predictive of treatment choice [22, 23].

\section{Re-operations}

The most important finding in terms of re-operations is an overall re-operation rate (percentage reoperated fractures among the surgically treated fractures) of almost $30 \%$ (29.8\%) for fractures in all segments of the tibia. Tibial shaft fractures had a higher re-operation rate $(37.0 \%)$ than proximal and distal tibial fractures $(24.0 \%$ and $26.8 \%$, respectively). The removal of internal fixation devices was the most commonly performed re-operation (258 of a total of 438 re-operations). In proximal tibial fractures, re-operations due to non-union were less common than re-operations due to malunion $(0.6 \%$ reoperated fractures versus $4.7 \%)$. This confirms the belief that metaphyseal bone often do not pose healing problems and non-union is uncommon. In tibial shaft fractures it was the other way around, re-operations due to non-union were more common than re-operations due to malunion (5.2\% reoperated fractures versus $2.2 \%$ ). This was also expected since cortical, diaphyseal bone often heals slower. In distal tibial fractures, re-operations due to nonunion and malunion were equally common ( $4.2 \%$ reoperated fractures each). As discussed later in the context of infection this might be due to diminished blood supply to the distal end of the extremities. Otherwise one might expect fractures of the metaphyseal bone of the distal tibia to have a low frequency of non-union as in the proximal tibia.

Probably the largest published study on re-operation rates after tibial fractures is the study by Henry et al. that presents re-operation rates and mortality after tibial plateau fractures [6]. Although no specific classification of fractures is reported in the study by Henry et al., it is stated in the paper that tibial plateau fractures correspond to $41 \mathrm{~A}-\mathrm{C}$ fractures in the AO/OTA classification. Henry et al. showed that $15.3 \%$ of the patients with tibial plateau fractures underwent reoperations. In the current study, the corresponding figures for proximal tibial fractures are $24 \%$. The higher numbers in the current study could be due to a longer follow-up period in the current study. In a prospective study of 275 consecutive surgically treated proximal tibial fractures, Kugelman 


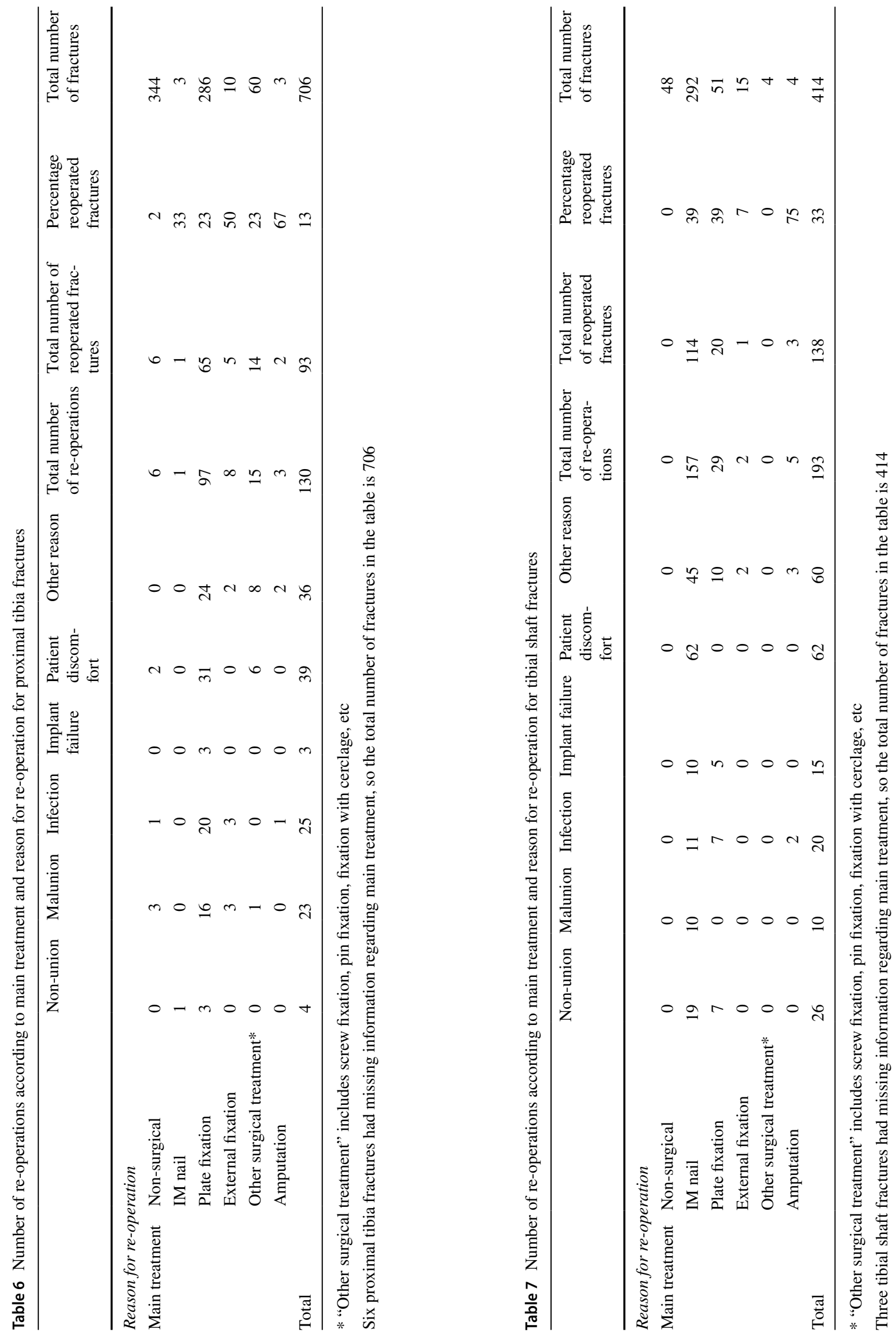


et al. reported a higher risk of complications for AO/OTA $\mathrm{C}$ fractures [4]. These findings are in agreement with the findings in the current study, where there was a high frequency of reoperated fractures among the $41 \mathrm{C}$ fractures (27.8-46.0\%).

In a systematic review, Henkelmann et al. report an infection rate of $9.8 \%$ (range 2.6-45.0\%) in proximal tibial fractures [24]. In the current study, $3.9 \%$ of proximal tibial fractures underwent re-operation due to infection. It is, however, difficult to compare the numbers from the current study with the systematic review, as the current study is based on re-operations and the re-operation rates were not reported in the review. In the current study, there was a peak of reoperations due to infection at the age of 51-80 years (6-8.3\% reoperated fractures). It is difficult to say what the cause of this might be. One possible explanation might be comorbidity, with diminished blood supply to the lower extremities. It is also possible that the soft-tissue injuries in this age group are underestimated.

Re-operations among tibial shaft fractures treated with an intramedullary nail and plate fixation in the current study were equally common (39\% each). However, it appears that fractures treated with an intramedullary nail underwent re-operation to a greater extent due to patient discomfort or "other reasons" which, in most cases, was related to the removal of hardware, whereas the tibial shaft fractures treated with plate fixation underwent re-operation to a greater extent due to non-union, infection and implant failure, which are re-operations due to more severe complications. The higher rate of re-operations due to more severe complications among the tibial shaft fractures treated with plate fixation might be due to larger surgical exposures compared with the percutaneous intramedullary nailing. Even though removal of hardware is not a severe complication, to correctly inform patients and to plan the health care system, it is important to know that a large part of patients treated with an intramedullary nail subsequently undergoes removal of hardware.

As far as we can tell, there is no other study with the same design, which makes it difficult to compare the results with previous studies. Fong et al. described that $13.5 \%$ of tibial shaft fractures underwent re-operation (not including hardware removal), which is similar to the re-operation rate in the current study (if removal of hardware is excluded) [2]. Costa et al. found that osteosynthesis with an intramedullary nail and plate fixation in distal extra-articular tibial fractures had similar functional results [3]. In the study by Costa et al., more secondary operations and infections were found among the fractures treated with plate osteosynthesis compared with the fractures treated with an intramedullary nail. Costa et al. defined distal extra-articular fractures as "a fracture within two Müller squares of the ankle joint". This renders a mixture of fractures that in the AO/OTA classification are

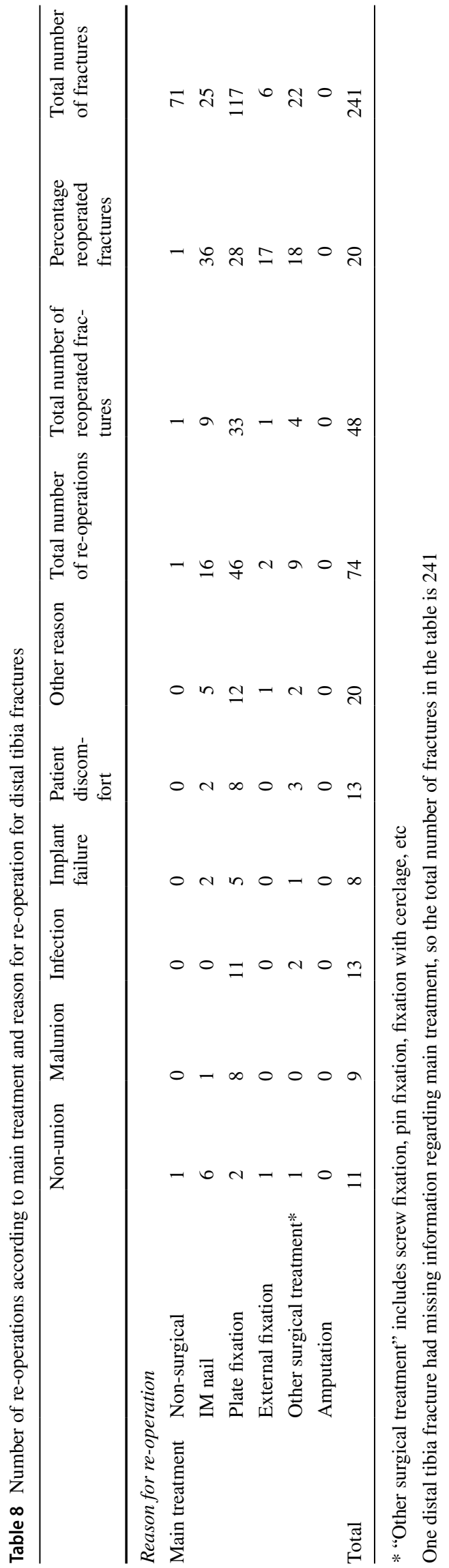


Fig. 2 Percentage reoperated fractures according to reason for re-operation and age

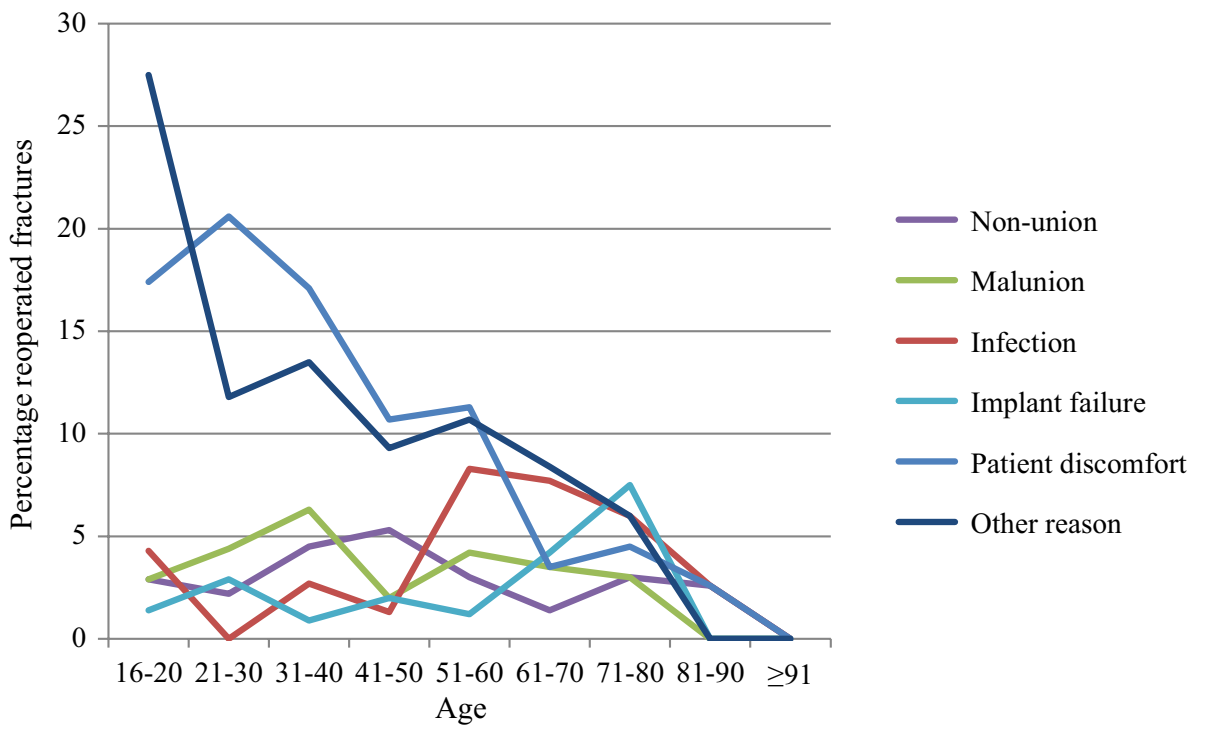

classified as tibial shaft and distal tibial fractures, which makes it difficult to compare the results with the results of the current study. In the study by Minhas et al., there was no difference in re-operation rates between fractures treated with intramedullary nailing compared with plate fixation [5]. In the current study, the tibial shaft fractures treated with an intramedullary nailing and plate fixation showed overall reoperation rate of 39\% each. The studies by Fong et al., Minhas et al. and the current study are all non-randomised studies where the treatment has been the responsible surgeon's choice. Fong et al. reported no difference in re-operation rates and Minhas et al. and the current study report equal re-operation rates among patients with tibial shaft fractures that were treated with intramedullary nailing and plate fixation, respectively. One possible interpretation of this is that, in clinical practice, orthopaedic surgeons select the fractures that are best treated with intramedullary nailing and plate fixation, respectively.

When the SFR was started in 2011, there were fewer options available for registration of reasons for re-operations. After a few years it was, however, assumed that most of the re-operations registered as due to "other reasons" were in fact due to patient discomfort. Therefore, the possibility to register re-operations as due to "patient discomfort" was added in February 2016. Since 2016 registrations of reoperations due to "other reasons" have become much more uncommon. So, it can be assumed that the majority of reoperations registered as "due to other reasons" were in fact performed due to patient discomfort. In Tables 1, 5, 6, 7, 8 and Fig. 2, re-operations "due to other reasons" and "due to patient discomfort" have a similar distribution, which also supports this assumption. However, we claim that this does not affect the results of the study.
The most obvious strength of the current study is that it presents a detailed description of the treatment and reoperation rates in a cohort of consecutive patients with tibial fractures during 5 years. The study includes all patients, all treatments, all types of fractures and all segments of the tibia. As the study does not exclude any type of patients, fractures or treatments, it describes the treatment and reoperation rates in a real-world setting. An additional strength is that Sahlgrenska University Hospital treats all tibial fractures in Gothenburg. The follow-up period of 2 to 8 years is comparatively long. Moreover, the classification of fractures for a sample of the cohort has been previously validated [12]. Thanks to the fact that the operation planning system and the medical charts were reviewed to ensure that all treatments including re-operations were registered in the SFR, high level of completeness was secured in the current study.

One limitation of the study is that it is based on a single hospital. The single centre design of the study was however a prerequisite for performing the above mentioned measures to achieve high completeness in registrations of both fractures, primary treatments and re-operations. Even though the single centre design is a limitation, the assurance of high completeness and validity of data in the study is a strength. Another limitation is that register-based data do not reveal every clinical aspect of the patients' status and performance, such as pain, mobility, range of motion and radiographic healing.

The current study is based on register data and reveals how tibial fractures are treated in current clinical practice at one large hospital in Sweden. It describes the re-operation frequencies of different fracture types and different treatments in the whole of the tibia. This kind of data cannot be used to compare different treatments or to draw conclusions 
about which treatment is associated with the lowest re-operation frequency. Nevertheless, it describes the reality in a systematic and detailed way that has not been done before.

\section{Conclusions}

This study describes the current treatment and re-operation rates of tibial fractures in Gothenburg, Sweden. For proximal and distal tibial fractures, plate fixation was the most commonly used surgical method and, for tibial shaft fractures, it was intramedullary nailing.

The study reveals an overall re-operation rate of $29.8 \%$ for fractures in all segments of the tibia. The re-operation rates described in the current study is important to be aware of to correctly inform patients and to plan the health care system.

Acknowledgements Open access funding provided by University of Gothenburg. We wish to thank all the orthopaedic surgeons at the affiliated departments for entering detailed data on busy working days.

Authors' contributions David Wennergren planned and conducted the study, conducted the search for, and registration of, missed treatments in the SFR, conducted the statistical calculations and created the tables and figures, analysed data and wrote the first draft of the manuscript. Carl Bergdahl planned and conducted the study, analysed data and revised the manuscript. Amanda Selse planned and conducted the study, conducted the search for, and registration of, missed treatments in the SFR, took part in analysing data and revised the manuscript. Jan Ekelund planned and conducted the study, conducted the statistical calculations and created the tables and figures, analysed data and revised the manuscript. Mikael Sundfeldt planned and conducted the study, analysed data and revised the manuscript. Michael Möller planned and conducted the study, analysed data and revised the manuscript. All authors have given final approval of the version to be published.

Funding For all authors, none was declared.

Availability of data and materials The datasets used and analysed during the current study are available from the corresponding author on reasonable request.

\section{Compliance with ethical standards}

Conflict of interest The authors declare that they have no conflict of interest.

Ethics approval The study was approved by the Central Ethical Review Board, Gothenburg (Reference number: 594-16).

Informed consent All patients were informed that registration in the Swedish Fracture Register took place and that they had the right to decline. According to Swedish legislation, National Quality Registers do not require signed consent from the individual registered patient.

Open Access This article is licensed under a Creative Commons Attribution 4.0 International License, which permits use, sharing, adaptation, distribution and reproduction in any medium or format, as long as you give appropriate credit to the original author(s) and the source, provide a link to the Creative Commons licence, and indicate if changes were made. The images or other third party material in this article are included in the article's Creative Commons licence, unless indicated otherwise in a credit line to the material. If material is not included in the article's Creative Commons licence and your intended use is not permitted by statutory regulation or exceeds the permitted use, you will need to obtain permission directly from the copyright holder. To view a copy of this licence, visit http://creativecommons.org/licenses/by/4.0/.

\section{References}

1. Wennergren D, Bergdahl C, Ekelund J, Juto H, Sundfeldt M, Moller M (2018) Epidemiology and incidence of tibia fractures in the Swedish Fracture Register. Injury 49(11):2068-2074. https ://doi.org/10.1016/j.injury.2018.09.008

2. Fong K, Truong V, Foote CJ, Petrisor B, Williams D, Ristevski B, Sprague S, Bhandari M (2013) Predictors of nonunion and reoperation in patients with fractures of the tibia: an observational study. BMC Musculoskeletal Disorders 14:103. https://doi. org/10.1186/1471-2474-14-103

3. Costa ML, Achten J, Griffin J, Petrou S, Pallister I, Lamb SE, Parsons NR, Fix DTTI (2017) Effect of locking plate fixation vs intramedullary nail fixation on 6-month disability among adults with displaced fracture of the distal tibia: the UK FixDT randomized clinical trial. JAMA 318(18):1767-1776. https://doi. org/10.1001/jama.2017.16429

4. Kugelman D, Qatu A, Haglin J, Leucht P, Konda S, Egol K (2017) Complications and unplanned outcomes following operative treatment of tibial plateau fractures. Injury 48(10):2221-2229. https:// doi.org/10.1016/j.injury.2017.07.016

5. Minhas SV, Ho BS, Switaj PJ, Ochenjele G, Kadakia AR (2015) A comparison of 30-day complications following plate fixation versus intramedullary nailing of closed extra-articular tibia fractures. Injury 46(4):734-739. https://doi.org/10.1016/j.injur y.2014.12.014

6. Henry P, Wasserstein D, Paterson M, Kreder H, Jenkinson R (2015) Risk factors for reoperation and mortality after the operative treatment of tibial plateau fractures in Ontario, 1996-2009. J Orthop Trauma 29(4):182-188. https://doi.org/10.1097/ BOT.0000000000000237

7. Study to Prospectively Evaluate Reamed Intramedullary Nails in Patients with Tibial Fractures I, Bhandari M, Guyatt G, Tornetta P, Schemitsch EH, Swiontkowski M, Sanders D, Walter SD (2008) Randomized trial of reamed and unreamed intramedullary nailing of tibial shaft fractures. J Bone Joint Surgery Am 90(12):25672578. https://doi.org/10.2106/JBJS.G.01694

8. Foote CJ, Guyatt GH, Vignesh KN, Mundi R, Chaudhry H, HeelsAnsdell D, Thabane L, Tornetta P 3rd, Bhandari M (2015) Which surgical treatment for open tibial shaft fractures results in the fewest reoperations? A network meta-analysis. Clin Orthop Relat Res 473(7):2179-2192. https://doi.org/10.1007/s11999-015-4224-y

9. Larsen LB, Madsen JE, Hoiness PR, Ovre S (2004) Should insertion of intramedullary nails for tibial fractures be with or without reaming? A prospective, randomized study with 3.8 years' followup. J Orthop Trauma 18(3):144-149

10. Wennergren D, Ekholm C, Sandelin A, Moller M (2015) The Swedish fracture register: 103,000 fractures registered. BMC Musculoskeletal Disorders 16:338. https://doi.org/10.1186/s1289 1-015-0795-8

11. Wennergren D, Moller M (2018) Implementation of the Swedish fracture register. Unfallchirurg 121(12):949-955. https://doi. org/10.1007/s00113-018-0538-z

12. Wennergren D, Ekholm C, Sundfeldt M, Karlsson J, Bhandari M, Moller M (2016) High reliability in classification of tibia fractures 
in the Swedish Fracture register. Injury 47(2):478-482. https://doi. org/10.1016/j.injury.2015.11.002

13. Juto H, Moller M, Wennergren D, Edin K, Apelqvist I, Morberg P (2016) Substantial accuracy of fracture classification in the Swedish fracture register: evaluation of AO/OTA-classification in 152 ankle fractures. Injury 47(11):2579-2583. https://doi. org/10.1016/j.injury.2016.05.028

14. Wennergren D, Stjernstrom S, Moller M, Sundfeldt M, Ekholm C (2017) Validity of humerus fracture classification in the Swedish fracture register. BMC Musculoskeletal Disorders 18(1):251. https ://doi.org/10.1186/s12891-017-1612-3

15. Juto H, Gartner Nilsson M, Moller M, Wennergren D, Morberg $P$ (2017) Evaluating non-responders of a survey in the Swedish fracture register: no indication of different functional result. BMC Musculoskeletal Disorders 18(1):278. https://doi.org/10.1186/ s12891-017-1634-x

16. Morgonskold D, Warkander V, Savvides P, Wihlborg A, Bouzereau M, Moller H, Gerdhem P (2019) Inter- and intra-rater reliability of vertebral fracture classifications in the Swedish fracture register. World J Orthop 10(1):14-22. https://doi.org/10.5312/wjo. v10.i1.14

17. Knutsson SB, Wennergren D, Bojan A, Ekelund J, Moller M (2019) Femoral fracture classification in the Swedish Fracture Register-a validity study. BMC Musculoskeletal Disorders 20(1):197. https://doi.org/10.1186/s12891-019-2579-z

18. Bergdahl C, Ekholm C, Wennergren D, Nilsson F, Moller M (2016) Epidemiology and patho-anatomical pattern of 2,011 humeral fractures: data from the Swedish Fracture Register. BMC Musculoskeletal Disorders 17(1):159. https://doi.org/10.1186/ s12891-016-1009-8

19. Kihlstrom C, Moller M, Lonn K, Wolf O (2017) Clavicle fractures: epidemiology, classification and treatment of 2422 fractures in the Swedish Fracture Register; an observational study. BMC Musculoskeletal Disorders 18(1):82. https://doi.org/10.1186/ s12891-017-1444-1

20. Mattisson L, Bojan A, Enocson A (2018) Epidemiology, treatment and mortality of trochanteric and subtrochanteric hip fractures: data from the Swedish fracture register. BMC Musculoskeletal Disorders 19(1):369. https://doi.org/10.1186/s12891-018-2276-3

21. Rundgren J, Bojan A, Mellstrand Navarro C, Enocson A (2020) Epidemiology, classification, treatment and mortality of distal radius fractures in adults: an observational study of 23,394 fractures from the national Swedish fracture register. BMC Musculoskeletal Disorders 21(1):88. https://doi.org/10.1186/s1289 1-020-3097-8

22. Müller M, Koch P, Nazarian S, Schatzker J (1990) The comprehensive classification of fractures of long bones. Springer, Berlin

23. Marsh JL, Slongo TF, Agel J, Broderick JS, Creevey W, DeCoster TA, Prokuski L, Sirkin MS, Ziran B, Henley B, Audige L (2007) Fracture and dislocation classification compendium-2007: orthopaedic Trauma Association classification, database and outcomes committee. J Orthop Trauma 21(10 Suppl):S1-133

24. Henkelmann R, Frosch KH, Glaab R, Lill H, Schoepp C, Seybold D, Josten C, Hepp P, TotAGASfA C, Joint S (2017) Infection following fractures of the proximal tibia-a systematic review of incidence and outcome. BMC Musculoskeletal Disorders 18(1):481. https://doi.org/10.1186/s12891-017-1847-z

Publisher's Note Springer Nature remains neutral with regard to jurisdictional claims in published maps and institutional affiliations. 